\title{
Invitro Treatment of Blue Ticks Using a Phytosubstance
}

\author{
Nyembezi Mgocheki*, Jenias Ndava \\ Biological Sciences Department, Faculty of Science, Bindura University of Science Education, Bindura, Zimbabwe
}

\author{
Email address: \\ nmgocheki@yahoo.com (N. Mgocheki) \\ "Corresponding author
}

\section{To cite this article:}

Nyembezi Mgocheki, Jenias Ndava. Invitro Treatment of Blue Ticks Using a Phytosubstance. American Journal of Entomology. Vol. 3, No. 4, 2019, pp. 66-69. doi: 10.11648/j.aje.20190304.11

Received: June 4, 2019; Accepted: July 4, 2019; Published: November 25, 2019

\begin{abstract}
Ticks are some of the most devastating ectoparasites of livestock causing several tick borne diseases. Management of ticks is increasing getting difficulty using synthetic acaricides due their rapid tolerance to the synthetic acaricides. Botanical acaricides are now used as an alternative management strategy to curb such problems. The blue tick, Rhiphicephalus (Boophilus) decolaratus, is a one-host tick that parasitizes cattle and vectors a debilitating protozoan parasite that causes babesiosis. Acaricidal properties of thyme were investigated on the cattle blue tick, R.B. decolaratus using various concentrations to establish the lethal dose concentration. The acaridal activity of thyme on ticks was monitored and recorded at two-hour intervals for 48 hours. Tick mortality was observed at all concentrations except the control. The lowest mortality rate was observed for $10 \mu \mathrm{l} / \mathrm{cm}^{3}$ while $40 \mu \mathrm{l} / \mathrm{cm}^{3}$ resulted in total tick mortality. The $\mathrm{LC}_{50}$ was established as $1,9 \mu 1 / \mathrm{cm}^{3}$. Significant differences $(p<0.01)$ were observed between concentrations, however the mortality was directly proportional to thyme concentration. The thyme oil dehydrated the ticks leading to death within 48 hours. The study thus concludes that thyme oil can be used as a complimentary or alternative acaricide in an integrated livestock program or where organic means are enforced or to as a way of minimizing tolerance of ticks to conventional acaricides.
\end{abstract}

Keywords: Acaricidal, Mortality, Lethal Dose, Thyme Oil, Bioassay

\section{Introduction}

For a long time, ticks have negatively impacted livestock producers causing a number of tick-borne diseases [1-2]. Ticks are responsible for causing and contributing to a number of different ailments and failure to control the tick population among the herd can lead to unpleasant health consequences for the herd. Without doubt, tick-borne diseases are the major limitation of cattle production [3] perpetuated by climate change pattern that continues to make an increasing amount of habitats suitable for tick distribution, growth and reproduction globally. Tick infestation in the herd can result in a number of tick-borne diseases such as lyme disease, heart water, gall sickness among others [4-5]. Ticks can cause skin irritation and fur loss in individual animals. In Sub Saharan Africa, livestock producers face high costs of production due to frequent use of acaricides. Many governments have provided highly subsidized regular plunge pool cattle dipping with synthetic acaricides like organophosphates, chlorinated hydrocarbon acaricides and carbamate acaricides which can be effective although other cattle owners opt to carry out individual spray races to manage ticks.

It is now widely accepted that some plants contain phytosubstances that exhibit properties that can repel, kill or alter certain physiological processes of different types of ticks. Some phytosubstances exhibit acaricidal properties hence can be used as sustainable and green methods of managing ticks. These phytosubstances are used alone or in an integrated program with synthetic acaricides. Synthetic acaricides are effective, however pose environmental and health hazards. Furthermore, ticks and mites can quickly develop tolerance to multiple acaricides increasing incidences of tick-borne diseases. In addition, the synthetic acaricides are costly, a huge limiting factor for many resource poor livestock owners in the tropics. In poor countries the dipping frequency is limited due unavailability of acaricides. Where resources are limited, or where organic methods are a preferred option, acaricidal phytosubstances can be recognized as a complimentary approach to the 
management of livestock health and to boost livestock production especially at community level. A number of plants contain phytosubstances that have acaricidal properties and among them is thyme (Thymus vulgaris) as well as its relatives that contain similar phytosubstances [6].

In vitro tests were carried out to test the acaricidal effects of T. vulgaris on the blue tick, Rhipicephalus (Boophilus) decolaratus, (a one-host tick) and the most common and damaging tick in Southern Africa [7]. The objectives of this study were $i$ ) to determine the lethal concentration $\left(\mathrm{LC}_{50}\right)$ for T. vulgaris oil on R. (B) decolaratus and ii) outline the mode of action for $T$. vulgaris oil on $R$. (B.) decolataus

\section{Materials and Methods}

Adult ticks $R$. (B) decolaratus) were collected from Shrewsbury Farm, Beatrice, Zimbabwe ( $18^{\circ} 9^{\prime} 56^{\prime \prime} \mathrm{S}, 30^{\circ}$ $\left.57^{\prime} 59^{\prime} \mathrm{E}, 1370 \mathrm{~m}\right)$ in the dry months when the frequency of dipping is low. In this area, cattle have a communal plunge pool dipping system and a cattle dipping, though enforced by law, is predominantly voluntary with some livestock producers often defaulting the dipping schedule. The ticks were collected using tweezers from the soft parts of cattle such as ears, the inner thighs, flanks, forelegs and abdomen. A total of 500 adult ticks were used. The bioassay was carried out on treated filter paper in ventilated petri dishes for 48 hours in a randomized block design in eight treatments with vegetable oil as a blank (Table 1). Twenty adult ticks were placed on sprayed filter paper in the ventilated petri dishes at $25^{\circ} \mathrm{C}, 60 \pm 5 \% \mathrm{RH}$ and 12: $12 \mathrm{~L}$ : D photoperiod. The percentage concentration was converted into $\log$ concentration $(\log (\mathrm{C} \%))$. Ticks were regarded dead if they did not move their legs upon probing with a pin. The proportion of dead ticks was determined using Eq 1:

$$
\text { Proportion, } P=\frac{\text { No.of dead ticks }}{\text { No.of dead ticks }+ \text { No.of live ticks }}
$$

The proportion, $P$, ranged from 0.02 to 1 .

Due to an uncertainty of a small number of dead ticks in the control and a small number of live ticks at high concentration, only values in the middle of the range were used to calculate the correction factor, Eq 2, to cater for those ticks that could have died independent of thyme oil:

Correction factor $=$ Proportion in treatment-Proportion in Control 1-Proportion in Control

\subsection{Data Analysis}

The $\mathrm{LC}_{50}$ was calculated using Probit analysis in excel while analysis of variance using $\mathrm{R}$ was used to estimate the differences in mean tick mortality.

\subsection{Results}

\subsubsection{Lethal Concentration}

Within 48 hours, $50 \%$ of the ticks were dead as a result of $1.9 \%$ concentration of thyme oil $\left(19 \mu \mathrm{l} / \mathrm{cm}^{3}\right)$ (Figure 1$)$.

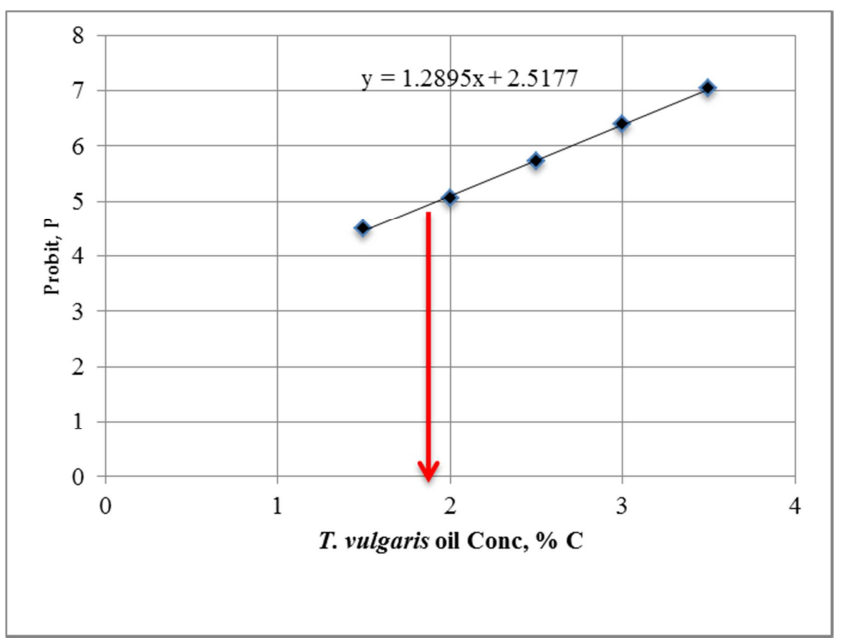

Figure 1. Determination of the lethal dose $\left(L C_{50}\right)$ for Thymus vulgaris oil on Rhipicephalus (Boophilus) decoralatus at various concentrations. The red arrow indicates the concentration that $1.9 \%$ T. vulgaris kills $50 \%$ of the ticks.

\subsubsection{Mean Acaricidal Activity of Thymus Vulgaris Oil}

There were significant differences in tick mortality between treatments $(\mathrm{p}<0.001)$ (Table 1$)$. Tick mortality was evident 15 hours post treatment. The lowest number of ticks was observed in the $10 \%$ concentration $(10 \mu \mathrm{l} / \mathrm{cm} 3)$ while there was total mortality in the $40 \%$ concentration $(40 \mu \mathrm{l} / \mathrm{cm} 3) 48$ hours post treatment.

\subsubsection{Effect of Thyme Oil on Ticks}

After two hours, ticks in all thyme treatments exhibited a haemorrhagic appearance losing their fluids. Eventually, all ticks lost their fluids and looked dehydrated and did not move when probed with a pin.

Table 1. Acaricidal activity of thyme oil (Thymus vulgaris) in vegetable oil on Rhipicephalus (Boophilus) decolaratus ticks (n=100).

\begin{tabular}{lll}
\hline Concentrations $\left(\boldsymbol{\mu l} / \mathbf{c m}^{3}\right)$ & Percent mortality $( \pm$ SD) & $\mathbf{L C}_{\mathbf{5 0}}\left(\boldsymbol{\mu l} / \mathbf{c m}^{\mathbf{3}}\right)$ \\
\hline 0 & $1 \pm 0.0$ & \\
1.0 & $25 \pm 0.54$ & \\
1.5 & $32 \pm 0.58$ & \\
2.0 & $53 \pm 0.69$ & 1.88 \\
2.5 & $77 \pm 1.2$ & \\
3.0 & $92 \pm 1.3$ & \\
3.5 & $98 \pm 1.34$ & \\
4.0 & $100 \pm 0.0$ & \\
\hline
\end{tabular}

\subsection{Discussion}

The results of this study are similar to the findings of [8-9] while [10] used a number of essential on Tetranychus cinnabarinus Boisduval, and achieved remarkable acaricidal effects of the essential oils from medicinal plants. Several authors have documented the use of essentials containing phytosubstances exhibiting acaricidal effects on a number of arthropod pests, for example [10- 20]. This is in response to an increasing tolerance of ticks to various synthetic acaricides [21]. It is imperative therefore to utilize such traditional methods of tick management to maintain livestock production.

The use of vegetable oil to necessitate proper blending in with thyme oil stabilized the thyme oil so it could stay on the 
filter paper at least up to the end of the experiment. Vegetable oils have been used in synthetic pesticides such as neem, azadiractin, among others [22-23]. Vegetable oils are ecofriendly posing no health hazards and additionally are easily available affordable and easy to handle.

The use of essential oils such as thyme oil as effective alternative or complimentary acaricides come at a time when livestock production is highly encouraged especially in the African continent where several natural plants containing acaricidal phytosubstances are found. This can improve livestock production by incorporating traditional means to supplement or to work parallel with synthetic acaricides. The mechanisms of acaricide resistance are yet to be well understood. However, the method by which thyme causes tick mortality through dehydration may be difficult for the arthropod pests to tolerate

\section{Conclusion(s)}

This study indicated high acaricidal activity of commercially made thyme oil mixed with vegetable oil. Thyme oil showed high acaricidal activity on $R$. (B) decolaratus ticks and can thus be used as a complimentary or alternative tick control management tool. Thyme oil therefore contains substances that are acaricidal to ticks and possibly to other parasitic arachnids. However it is recommended that further studies be carried to establish other compounds in thyme other than thymol that contribute to the acaricidal nature of the phytosubstance.

\section{Acknowledgements}

The authors would like to express their sincere gratitude to the owner of Shrewsbury farm, Mr. K Basira who allowed collection of ticks from his herd. Many thanks also go to $\mathrm{Mr}$ Chomu for actively participating in the tick collection.

This study did not get any funding from public sources.

\section{Conflict of Interest}

The authors declare that they have no competing interests.

\section{Notes/Thanks/Other Declarations}

Our appreciation goes to Mr. K Basira of Shrewsbury farm for permission to move with his team during tick collection. We also thank all those people of Beatrice district who shared with us their information during the fieldwork.

\section{References}

[1] Bekalu, G. E. and Angesom, H. D., (2016). Review on the Impact of Ticks on Livestock Health and Productivity. Journal of Biology, Agriculture and Healthcare 6 (22), 1.

[2] Meltzer M. I, Norval, R. A. and Donachie, P. L., (1995).
Effects of tick infestation and tick-borne disease infections (heartwater, anaplasmosis and babesiosis) on the lactation and weight gain of Mashona cattle in southeastern Zimbabwe. Tropical Animal Health Production 27 (3), 129-44.

[3] Pegram, R. G, James, A. D., Oosterwijk, G. P. and Killorn, K. J., (1991). Studies on the economics of ticks in Zambia. Experimental Applications in Acarology, 12, 9-26.

[4] Piesman, J. and Eisen, L., (2008), Prevention of tick-borne diseases. Annual Reviews of Entomology 53, 323-343.

[5] Smeenk, I., Kelly, P. J., Wray, K., Musuka, G., Trees, A. J. and Jongejan, F., (2000). Babesia bovis and B. bigemina DNA detected in cattle and ticks from Zimbabwe by polymerase chain reaction. Journal of South African Veterinary Association, 71 (1), 21-4.

[6] El-Gengaihi, S. E., Amer, S. A. A. and Mohamed, S. M., (1996). Biological Activity of Thyme Oil and Thymol against Tetranychus urticae Koch. Anzeiger Für Schädlingskunde, Pflanzenschutz, Umweltschutz 69 (7), 157-159.

[7] Norval, R. A., Fivaz, B. H., Lawrence, J. A., Daillecourt. T., (1983). Epidemiology of tick-borne diseases of cattle in Zimbabwe. I. Babesiosis. Tropical Animal Health Production 15 (2), 87-94.

[8] Tak, J. H.; Jovel, E.; Isman, M. B. (2016), Contact, fumigant, and cytotoxic activities of thyme and lemongrass essential oils against larvae and an ovarian cell line of the cabbage looper, Trichoplusia ni. Journal of Pesticide Science 89, 183-193.

[9] Balan Banumathi, Balasubramanian Malaikozhundan, Baskaralingam Vaseeharan, Invitro acaricidal activity of ethnoveterinary plants and greensynthesis of zinc oxide nanoparticles against Rhipicephalus (Boophilus)microplus, Veterinary parasitology DOI: 10.1016/j.vetpar.2015.12.003

[10] Sertkaya, E., Kaya, K., Soylu, S., (2010), Acaricidal activities of the essential oils from several medicinal plants againstthe carmine spider mite (Tetranychus cinnabarinus Boisd.)(Acarina: Tetranychidae). Ind. Crops Prod. 31, 107112.

[11] Tak, J. H., Jovel, E., Isman, M. B., (2016). Comparative and synergistic activity of Rosmarinus officinalis L. essential oilconstituents against the larvae and an ovarian cell line of the cabbage looper, Trichoplusia ni (Lepidoptera: Noctuidae). Pest Management Science 72, 474-480.

[12] Ma, W. B., Feng, J. T., Jiang, Z. L., Zhang, X., (2014). Fumigant activity of 6 selected essential oil compounds and combined effect of methyl salicylate and transcinnamaldehyde against Culex pipiens pallens. Journal of American Mosquito Control, 30, 199-203.

[13] Wu, Y., Zhang, W. J., Huang, D. Y., Wang, Y., Wei, J. Y., Li, Z. H., Sun, J. S., Bai, J. F., Tian, Z. F., Wang, P. J., (2015). Chemical compositions and insecticidal activities of Alpinia kwangsiensis Essential Oil against Lasioderma serricorne. Molecules 20, 21939-21945.

[14] Miresmailli, S., Bradbury, R., Isman, M. B., (2006). Comparative toxicity of Rosmarinus officinalis L. essential oil and blends of its major constituents against Tetranychus urticae Koch (Acari: Tetranychidae) on two different host plants. Pest Management Science, 62, 366-371. 
[15] Mansour, F., Azaizeh, H., Saad, B., Tadmor, Y., Abo-Moch, F., Said, O., (2004). The potential of Middle Eastern flora as a source of new safe bio-acaricides to control Tetranychus cinnabarinus, the carmine spider mite. Phytoparasitica 32, 6672.

[16] Ranger, C. M., Reding, M. E., Oliver, J. B., Moyseenko, J. J., Youssef, N., Krause, C. R., (2013). Acute toxicity of plant essential oils to scarab larvae (Coleoptera: Scarabaeidae) and their analysis by gas chromatography-mass spectrometry. Journal of Economic Entomology 106, 159-167.

[17] Blenau, W. Rademacher, E. Baumann, A., (2012). Plant essential oils and formamidines as insecticides/acaricides: What are the molecular targets? Apidologie 43, 334-347.

[18] Seo, S. M., Park, H. M., Park, I. K., (2012). Larvicidal activity of ajowan (Trachyspermum ammi) and Peru balsam (Myroxylon pereira) oils and blends of their constituents against mosquito, Aedes aegypti, acute toxicity on water flea, Daphnia magna, and aqueous residue. Journal of Agriculture and Food Chemistry 60, 5909-5914.

[19] Tabari, M. A., Youssefi, M. R., Barimani, A., Araghi, A., (2015). Carvacrol as a potent natural acaricide against Dermanyssus gallinae. Parasitology Research 114, 38013806.
[20] Opiro, R., Osinde, C, Okello-Onen, J. and Akol, A. M., (2013). Tick-repellent properties of four plant species against Rhipicephalus appendiculatus Neumann (Acarina: Ixodidae) tick species. E3 Journal of Agricultural Research and Development 3 (2), 017-021.

[21] Janadaree Bandara, K. M. U. and Parakrama Karunaratne, S. H. P., (2017). Mechanisms of acaricide resistance in the cattle tick Rhipicephalus (Boophilus) microplus in Sri Lanka. Pesticide Biochemistry and Physiology 139, 68-72

[22] Singh, A., Khare, A. and Singh, A. P., (2012). Use of Vegetable Oils as Biopesticide in Grain Protection-A Review. Journal of Biofertilizers and Biopesticides 3, 114. doi:10.4172/2155-6202.1000114.

[23] Giglioti, R., Forim, M. R., Oliveira, H. N., Chagas, A. C. S., Ferrezini, J., Brito, L. G., Falcoski, T. O. R. S., Albuquerque L. G. and Oliveira, M. C. S. (2011). In vitro acaricidal activity of neem (Azadirachta indica) seed extracts with known azadirachtin concentrations against Rhipicephalus microplus. Veterinary Paraitology 181 (2-4), 309-315. 